\title{
Selective oviposition in fertilized seed of Ilex integra by the wasp Macrodasyceras hirsutum (Hymenoptera: Torymidae)
}

\author{
Etsuro TAKAGI ${ }^{1}$, KaZunobu IGUCHI ${ }^{2}$, Masanori SUZUKI ${ }^{2}$ and Katsumi TOGASHI ${ }^{1}$ \\ ${ }^{1}$ Laboratory of Forest Zoology, Graduate School of Agricultural and Life Sciences, The University of Tokyo, Yayoi, Bunkyo-ku, \\ Tokyo 113-8657, Japan; e-mail: takagi@fr.a.u-tokyo.ac.jp \\ ${ }^{2}$ University Forest in Chiba of Graduate School of Agricultural and Life Sciences, The University of Tokyo, Kamogawa City, \\ Chiba Prefecture, 299-5503, Japan
}

Key words. Selective oviposition, Macrodasyceras hirsutum, Hymenoptera, Torymidae, seed parasitoid wasp, seed predation, Ilex integra, seed fertilization, GLMM

\begin{abstract}
It is speculated that the wasps that attack the seeds of gymnosperm trees (conifers) before they are fertilized can induce unfertilized seeds to accumulate storage material whereas those that attack after the seeds are fertilized selectively oviposit in fertilized seeds. Moreover, in the case of the wasps that oviposit after fertilization of seed, the presence of unfertilized seeds and seedless fruit may increase plant fitness via reduced parasitism of the viable seed. To determine the relationship between the two strategies, host manipulation or selective oviposition, and the time of fertilization of the seeds of angiosperm host plants, fertilized seed of Ilex integra Thunb. was dissected out of berries either immediately after the flight of the seed wasp Macrodasyceras hirsutum Kamijo in the field or the death of adults in the laboratory. The wasps oviposited mostly in fertilized seeds and rarely in unfertilized seeds. Unfertilized seeds, produced by flowers enclosed in pollen exclusion bags, and then exposed to wasps did not contain immature wasps or storage material, which indicates that the wasp did not oviposit in unfertilized seeds. These results support the above mentioned hypothesis and indicate that the substantial proportion of seedless berries do not function as an egg sink.
\end{abstract}

\section{INTRODUCTION}

Some insects insert their eggs into seeds and their larvae consume its storage matter, often inhibiting the survival and growth of seeds and seedlings and so reduce the fitness of host plants (Janzen, 1970). When the larvae cannot easily move from seed to seed, selective oviposition into the most nutritious seeds, such as fertilized rather than unfertilized seeds, may increase the fitness of the parents, because there is more storage matter in fertilized seeds (Desouhant, 1998; Stamps \& Linit, 2002). In gymnosperms (conifers), such as Abies balsamea (L.) Miller, Juniperus phoenicea L. and Pinus contorta Douglas ex Loudon, it takes from one month to one year for pollen to fertilize ovules after pollination. Therefore, parasitoid wasps may oviposit into both pollinated and unpollinated ovules that cannot be distinguished from one another at the time of oviposition (Rouault et al., 2004). Once fertilization has occurred, unpollinated ovules usually quickly degenerate but if they contain wasp larva they do not degenerate and even accumulate energy reserves, as is the case when Megastigmus spermotrophus Wachtl (Hymenoptera: Torymidae) larvae are present in unfertilized ovules of Douglas fir (Pseudotsuga menziesii (Mirbel) Franco) (von Aderkas et al., 2005a, b). However, when the seed wasp lays its eggs after the seeds are fertilized they may differentiate between fertilized and unfertilized megagametophytes (Rouault et al., 2004). Rouault et al. (2004) hypothesized that selective oviposition and host manipulation by wasps is closely associated with when in a season wasps lay their eggs relative to host reproductive phenology. On the other hand, some angiosperms, although costly in terms of resources, have non-viable seeds and/or fruits containing non-viable seeds, which serve as a decoy for seed predators or as a sink for eggs deposited by them, resulting in the increased likelihood of viable seeds surviving to seed dispersal (Zangerl et al., 1991; Traveset, 1993; Ghazoul \& Satake, 2009).

Macrodasyceras hirsutum Kamijo (Hymenoptera: Torymidae) is a wasp that attacks only the seed of Ilex integra Thunb. (Aquifoliaceae). The genus Macrodasyceras, defined by Kamijo (1981), was synonymized with the genus Bootania Bouček (1988), but re-established by Grissell \& Desjardins (2002) as a discrete genus of chalcids that only attack Ilex seeds. Adult females of Macrodasyceras hirsutum that have overwintered oviposit into seeds from late May through June. Larvae only develop in developing seeds in July and there are berries on Ilex integra in autumn that contain only unfertilized seeds. Three hypotheses have been proposed to account for the presence of immature larvae of Macrodasyceras hirsutum in developing seeds of Ilex integra. First, female wasps oviposit into both fertilized and unfertilized seeds, and they and/or their progeny induce plants to accumulate storage material in unfertilized seeds. Secondly, although they oviposit into fertilized and unfertilized seeds, the progeny in unfertilized seeds die soon after hatching, resulting in enhanced survival of fertilized seeds (Zangerl et al., 1991; Traveset, 1993; Ghazoul \& Satake, 2009). Third, female wasps only oviposit into fertilized seeds. To determine which hypothesis explains the concentra- 

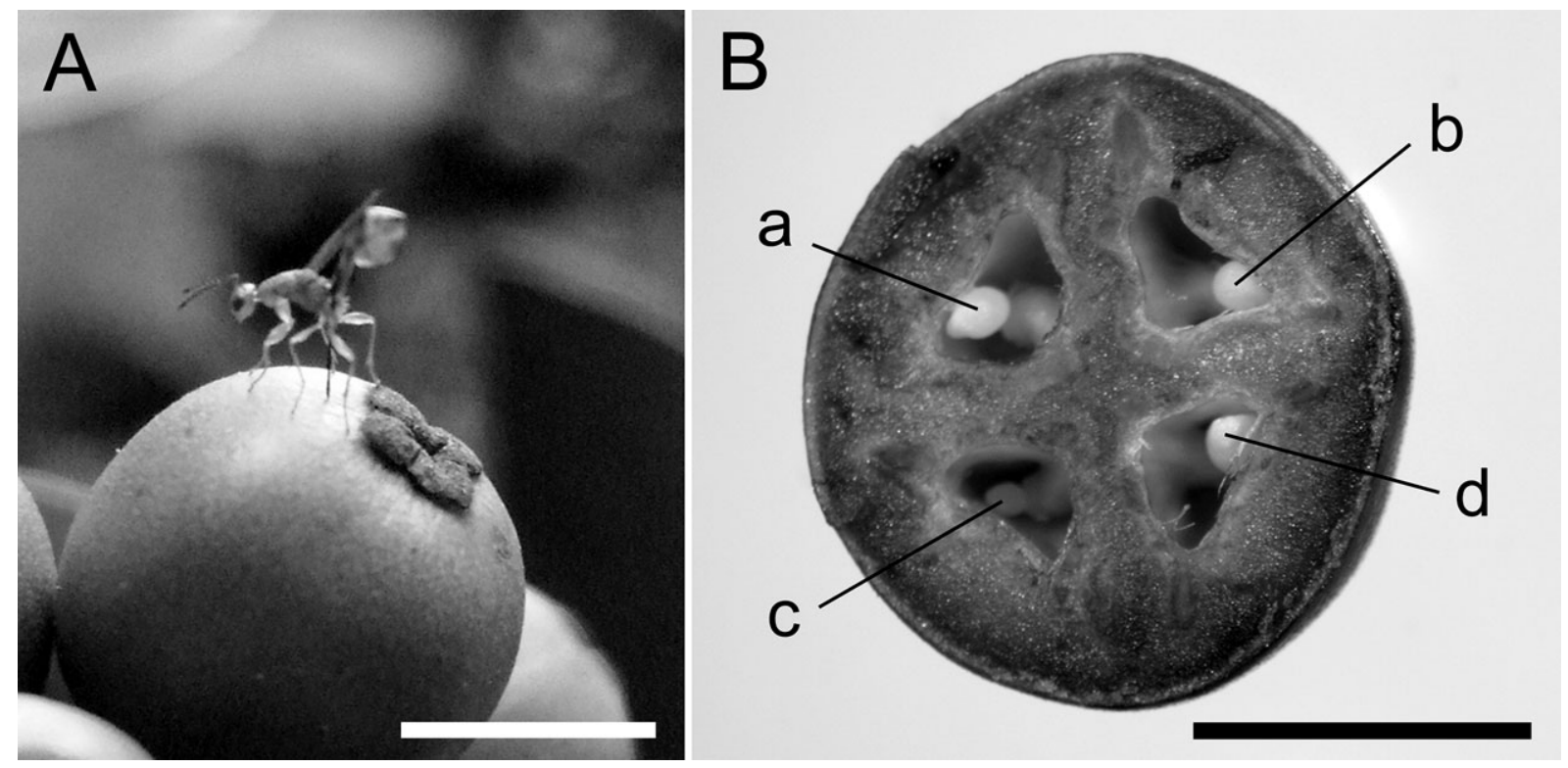

Fig. 1. Photograph of a Macrodasyceras hirsutum female in the process of inserting its ovipositor into an Ilex integra berry (A). Cross-section of an Ilex integra berry made on 21 May 2008 before the wasps of the overwintered generation started to oviposit (B). The berry contains an undeveloped seed (c) and three developing seeds ( $\mathrm{a}, \mathrm{b}$ and $\mathrm{d}$ ) each enclosed in an endocarp. Bars $=5 \mathrm{~mm}$.

tion of wasp larvae in developing seeds and in particular to test Rouault et al. (2004) hypothesis, the distribution of eggs between fertilized and unfertilized seeds in the field and laboratory immediately after the first period of oviposition, and whether they would oviposit into unfertilized seeds obtained by means of the use of pollen exclusion bags in the field, were investigated. Possible reasons for retaining berries with unfertilized seeds are also discussed.

\section{MATERIAL AND METHODS}

\section{Study area}

The study was carried out in a hilly, rural area of Kimitsu and Kamogawa Cities, Chiba Prefecture, which includes the Forest of Tokyo University at Chiba, where coniferous plantations, natural broad-leaved evergreen and coniferous forests and secondary broad-leaved forests cover the hills. Ilex integra occurs sparsely in the forests and is sometimes planted near houses in the study area. In 2007, 40 trees were located in this area, 38 of which were in the forest and two near houses.

\section{Seed wasp}

Macrodasyceras hirsutum (Hymenoptera: Torymidae) only eats the seed of Ilex integra and never damages the flesh of the berry (Kamijo, 1981). The adults appear twice a year. The overwintered generation lays 1 to 5 eggs in each seed from late May through to mid-June (Figs 1A and 2). Only one larva develops in a seed, of which only 0 to $62.5 \%$ complete their development and emerge as adults in August (first generation), the remainder complete their development the following year. The adults that emerge in August lay their eggs in the remaining immature seeds that do not contain wasp larvae. Therefore, both first and second generation larvae can be found overwintering in seeds (Takagi \& Togashi, unpubl.).

\section{Host plant}

Ilex integra is a canopy tree of broad-leaved evergreen forest in central and western Japan (Miyawaki et al., 1983). It is dioe- cious and blooms from late March through to mid-April. Peduncles bearing female flowers emerge from the leaf axils of oneyear-old twigs. Immediately after flowering, the ovary starts to develop into a spherical berry. Each berry usually has four cavities enclosed by endocarps, each of which contains one ovule at the time of anthesis. Ovules develop into viable seeds covered by hard endocarps (pyrenes) within the berry and it is possible to discriminate between developing and undeveloped seeds on the basis of their morphology and size in mid-May, before the wasps emerge (Fig. 1B). As double-fertilization initiates growth and differentiation of the ovule (seed growth) (Esau, 1977), the presence of two types of seeds suggests that Ilex integra egg nuclei fuse with sperm nuclei before the wasps emerge. The berries are green in mid-spring and throughout summer, turning red as they ripen in autumn. Each Ilex integra tree shows a marked yearly fluctuation in berry production (Katsumata et al., 1997). Birds consume the red berries and disperse the seeds (Fukui, 1995). Nineteen and 21 of the 40 Ilex integra trees bore berries in April 2008 and 2009, respectively.

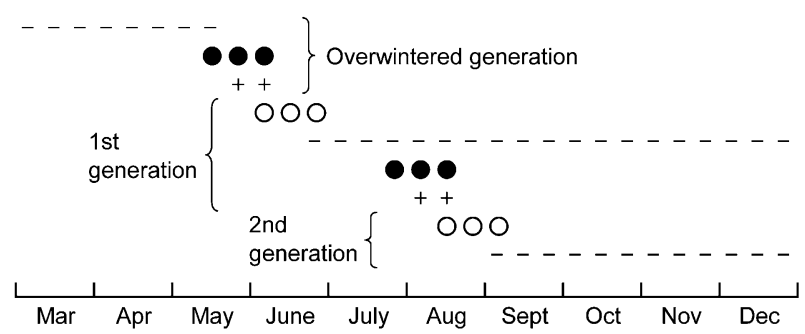

Fig. 2. Diagram of the life history of the seed wasp Macrodasyceras hirsutum. Adults (+) emerge from Ilex integra berries twice a year. Adults of the over-wintered generation appear between May and June and deposit eggs (O), which give rise to the first generation to develop in the seeds. Some of the first generation individuals emerge as adults, whereas the others overwinter as larvae (-). Larvae of the second generation also overwinter in seeds. After overwintering, they pupate $(\bullet)$. 
The relationships between the size of a berry, number of fertilized seeds and oviposition into fertilized and unfertilized seeds by wasps in the field and laboratory

On 16 June 2008 and 18 June 2009, immediately after the overwintered wasps had emerged and oviposited, three twigs were randomly collected from each of 9 and 14 trees, respectively. The twigs, the cut ends of which were placed in water, were kept at $10^{\circ} \mathrm{C}$ and under a constant 8 -h photophase and 16 -h scotophase. The major- and minor-axis lengths and heights of five berries on each twig were measured to the nearest $0.05 \mathrm{~mm}$ using a vernier calliper. The berries were dissected under a microscope and the lengths of the seeds (or ovules) and the presence or absence of wasp eggs and larvae in each seed were recorded. Dissection was completed by 11 July 2008 and 8 July 2009.

The following experiment was done to determine whether wasps selectively lay eggs in fertilized seeds. On 13 May 2009 , before the wasps started to lay eggs, three branches on each of two trees were enclosed in bags made of polyester gauze (Toray tetoron ${ }^{\circledR}$ Honey queen $\# 9000$; Toray Industries, Inc.) to isolate the berries from the wild wasp population. On 22 May, three twigs with 19 berries were harvested from the bags and the cut ends placed in a sponge-like porous block $(7.5 \times 11 \times 8 \mathrm{~cm}$,

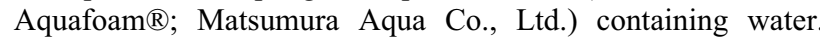
Twigs with berries and 17 female wasps randomly collected in the field were placed in a transparent plastic container $(8 \times 14.5$ $\mathrm{cm}$ at bottom and top, and $9 \times 16 \mathrm{~cm}$ half way up the $20 \mathrm{~cm}$ tall container) and kept at $25^{\circ} \mathrm{C}$ and under a 16 -h photophase and 8-h scotophase. This experiment was repeated using two twigs with 20 berries harvested from the bags and 18 females randomly collected form the field on 26 May. On 29 May and 2 June, when all the wasps had died, in experiments 1 and 2, respectively, all berries were dissected and the presence of eggs in fertilized and unfertilized seeds recorded. All dissections were completed by 4 June 2009 . After the wasps ceased laying eggs in the field, 14 and 15 berries in the bags on each tree were randomly collected and dissected to confirm that there were no wasp eggs in the berries prior to their use in the experiment.

Oviposition response of the wasps to unfertilized seeds in the field

To determine whether the wasp oviposits in unfertilized seeds in the field and whether unfertilized seeds containing wasp larvae accumulate storage material, three branches of each of three Ilex integra trees were individually enclosed in pollen exclusion bags made of nonwoven cloth (KC200 Kimgurad onestep ${ }^{\circledR}$, Bacterial filtration efficiency (BFE) $93.2 \%$; KimberlyClark Health Care Inc.) before anthesis on 31 March 2009. On 19 May 2009, between the end of the anthesis and when the overwintered wasps emerged, some berries were exposed by removing the bags and others were confined in new bags made of polyester gauze (Toray Tetoron ${ }^{\circledR}$ Honey queen \#9000; Toray Industries, Inc.) immediately after removing the bags used to isolate the berries from the wasps. Twigs with berries were harvested on 16 July 2009 , between the end of the flight season of the overwintered generation and the beginning of that of the first generation. They were placed in transparent plastic bags and kept at $10^{\circ} \mathrm{C}$ under a constant photoperiod of 8-h photophase and 16-h scotophase. The seeds in all the berries were dissected and the presence or absence of immature wasps and the length of the seeds recorded. Dissection was completed by 2 August 2009.

\section{Statistical analysis}

Comparison of the proportions of fertilized and unfertilized seeds that contained wasp larvae in the field and laboratory was
TABLE 1. Different numbers of endocarps and fertilized seeds in individual berries of Ilex integra.

\begin{tabular}{|c|c|c|c|c|c|c|c|}
\hline \multirow{2}{*}{$\begin{array}{l}\text { No. of endocarps } \\
\text { in a berry }\end{array}$} & \multicolumn{6}{|c|}{ No. of fertilized seeds in each berry } & \multirow{2}{*}{ Total } \\
\hline & 0 & 1 & 2 & 3 & 4 & 5 & \\
\hline 2 & 0 & 0 & 1 & - & - & - & 1 \\
\hline 3 & 1 & 3 & 5 & 7 & - & - & 16 \\
\hline 4 & 24 & 28 & 45 & 81 & 142 & - & 320 \\
\hline 5 & 1 & 0 & 0 & 0 & 3 & 4 & 8 \\
\hline Total & 26 & 31 & 51 & 88 & 145 & 4 & 345 \\
\hline
\end{tabular}

conducted using Fisher's exact test. This test was also used to compare wasp oviposition in artificially unfertilized seeds and untreated seeds, including naturally fertilized and unfertilized seeds in the field. Pearson's correlation coefficient was used to determine whether there is a relationship between the arcsine transformed proportion of damaged, fertilized seeds and unfertilized seeds with wasp eggs. To determine the effect of the number of fertilized seeds and endocarps on berry size in $\mathrm{mm}^{3}$, calculated as (major-axis length) $\times$ (minor-axis length) $\times$ (height) $\times \pi / 6$, in each of the two years, a generalized linear mixed model (GLMM) was used, in which it was assumed that berry size followed a Gaussian-distribution, the number of fertilized seeds and endocarps and their interaction had fixed effects and tree had a random effect. GLMM was also used to determine the effect of the number of fertilized seeds in a berry and the berry size in $\mathrm{mm}^{3}$ on the number of seeds in a berry with larvae, assuming that the number of seeds with larvae was binomially-distributed, the number of fertilized seeds, the berry size and their interaction had fixed effects and tree had a random effect. Calculation was made using R 2.4.1 and the lme4 package. The best model was selected using the AIC value and likelihood ratio test.

\section{RESULTS}

\section{The relationships between the size of a berry, number of fertilized seeds and oviposition into fertilized and unfertilized seeds by wasps in the field and laboratory}

The relation between berry size and the number of fertilized seeds

A total of 345 berries collected in the field had two to five endocarps (Table 1). Out of 1,370 endocarps dissected $998(72.8 \%)$ had 1.0 to $4.0 \mathrm{~mm}$ long, developing seeds containing a watery substance and the remaining $372(27.2 \%)$ had 0.5 to $1.0 \mathrm{~mm}$ long, undeveloped seeds composed of hard tissue (Table 1). The former and latter were judged as fertilized and unfertilized seeds, respectively, on the basis of their morphology and size. Ilex integra berries contain from zero to five fertilized seeds (Table 1).

In 320 fruits with four endocarps, the mean ( $\pm \mathrm{SE}$ ) major- and minor-axis lengths and height of the berries with one or more fertilized seeds were $8.38( \pm 0.04), 8.85$ $( \pm 0.04)$ and $9.44( \pm 0.05) \mathrm{mm}$, respectively and those with no fertilized seeds were $8.54( \pm 0.10), 9.01( \pm 0.10)$ and $9.28( \pm 0.15) \mathrm{mm}$, respectively. The measurements were $8.60,8.85$, and $8.65 \mathrm{~mm}$ for one berry with two endocarps, $8.03( \pm 0.14), 8.40( \pm 0.15), 9.18( \pm 0.24) \mathrm{mm}$ for 16 berries with three endocarps and $8.79( \pm 0.19)$, $9.06( \pm 0.22)$ and $9.81( \pm 0.22) \mathrm{mm}$ for eight berries with five endocarps, respectively. The results of GLMM sug- 
TABLE 2. Results showing the preference of Macrodasyceras hirsutum wasps for ovipositing in fertilized seed of Ilex integra.

\begin{tabular}{|c|c|c|c|c|c|c|}
\hline \multirow{2}{*}{ Year } & \multirow{2}{*}{ Tree code } & \multirow{2}{*}{$\begin{array}{c}\text { No. of seeds } \\
\text { examined }\end{array}$} & \multicolumn{2}{|c|}{ No. (\%) of fertilized seeds } & \multicolumn{2}{|c|}{ No. (\%) of unfertilized seeds } \\
\hline & & & With eggs & Without eggs & With eggs & Without eggs \\
\hline \multirow[t]{10}{*}{2008} & F3 & 54 & $13(24.1)$ & $37(68.5)$ & $0(0)$ & $4(7.4)$ \\
\hline & $\mathrm{F} 4$ & 60 & $0(0)$ & $50(83.3)$ & $0(0)$ & $10(16.7)$ \\
\hline & F5 & 62 & $2(3.2)$ & $50(80.6)$ & $0(0)$ & $10(16.1)$ \\
\hline & F11 & 61 & $6(9.8)$ & $53(86.9)$ & $0(0)$ & $2(3.3)$ \\
\hline & F16 & 59 & $0(0)$ & $48(81.4)$ & $0(0)$ & $11(18.6)$ \\
\hline & F19 & 58 & $0(0)$ & $16(27.6)$ & $0(0)$ & $42(72.4)$ \\
\hline & F20 & 62 & $0(0)$ & $45(72.6)$ & $0(0)$ & $17(27.4)$ \\
\hline & $\mathrm{F} 23$ & 60 & $0(0)$ & $55(91.7)$ & $0(0)$ & $5(8.3)$ \\
\hline & F25 & 57 & $0(0)$ & $47(82.5)$ & $0(0)$ & $10(17.5)$ \\
\hline & Subtotal & 533 & $21(3.9)$ & $401(75.2)$ & $0(0)$ & $111(20.8)$ \\
\hline \multirow[t]{16}{*}{2009} & F2 & 61 & $53(86.9)$ & $2(3.3)$ & $1(1.6)$ & $5(8.2)$ \\
\hline & F11 & 59 & $26(44.1)$ & $3(5.1)$ & $1(1.7)$ & $29(49.2)$ \\
\hline & F19 & 59 & $39(66.1)$ & $5(8.5)$ & $0(0)$ & $15(25.4)$ \\
\hline & F20 & 60 & $25(41.7)$ & $10(16.7)$ & $1(1.7)$ & $24(40.0)$ \\
\hline & F23 & 59 & $50(84.7)$ & $5(8.5)$ & $1(1.7)$ & $3(5.1)$ \\
\hline & F25 & 59 & $45(76.3)$ & $8(13.6)$ & $0(0)$ & $6(10.2)$ \\
\hline & F29 & 60 & $9(15.0)$ & $35(58.3)$ & $0(0)$ & $16(26.7)$ \\
\hline & \#93 & 59 & $35(59.3)$ & $14(23.7)$ & $0(0)$ & $10(16.9)$ \\
\hline & Goda & 60 & $2(3.3)$ & $0(0)$ & $0(0)$ & $58(96.7)$ \\
\hline & Kiwa & 60 & $0(0)$ & $42(70.0)$ & $0(0)$ & $18(30.0)$ \\
\hline & Kura \#1 & 60 & $27(45.0)$ & $7(11.7)$ & $0(0)$ & $26(43.3)$ \\
\hline & Kura \#2 & 60 & $16(26.7)$ & $20(33.3)$ & $0(0)$ & $24(40.0)$ \\
\hline & Tsu \#2 & 61 & $26(42.6)$ & $23(37.7)$ & $0(0)$ & $12(19.7)$ \\
\hline & Tsu \#3 & 60 & $32(53.3)$ & $17(28.3)$ & $0(0)$ & $11(18.3)$ \\
\hline & Subtotal & 837 & $385(46.0)$ & $191(22.8)$ & $4(0.5)$ & $257(30.7)$ \\
\hline & Total & 1370 & $406(29.6)$ & $592(43.2)$ & $4(0.3)$ & $368(26.9)$ \\
\hline
\end{tabular}

gest that berry size does not depend on the number of fertilized seeds or endocarps within a berry. Although the model incorporating the number of fertilized seeds and endocarps without interaction minimized the AIC value $(\mathrm{AIC}=2312.1)$, it did not differ significantly from the model that only included trees $(\mathrm{AIC}=2312.6$, likelihood ratio test, $\chi^{2}=4.52$, $\left.\mathrm{df}=2, \mathrm{P}=0.104\right)$ in 2008. GLMM results for 2009 indicated that the model that only included trees minimized the AIC value $(\mathrm{AIC}=1286.1)$.

Oviposition into fertilized and unfertilized seeds by wasps in the field and laboratory

Dissection of seeds from berries collected in the field revealed the presence of wasp eggs but not larvae. The proportion of fertilized seeds with wasp eggs (406/998) was significantly greater than that of unfertilized seeds (Fisher's exact test, $\mathrm{P}<0.001$ ) (Table 2). Only 4 of the 14 trees sampled had 1 unfertilized seed with wasp eggs. Oviposition into unfertilized seeds was observed on trees where the percentage of fertilized seeds with eggs ranged from 71.4 to $96.4 \%$, although there was no significant correlation between the proportion of damaged, fertilized seeds and the proportion of unfertilized seeds with wasp eggs $(r=0.385, \mathrm{P}=0.17)$.

The GLMM including the number of fertilized seeds and trees in 2009 minimized the AIC values (AIC = 201.7, regression coefficient \pm SE for the number of fertilized seeds $=0.919 \pm 0.102, \mathrm{P}<0.001)$, indicating that the number of fertilized seeds had a significant effect on the number of seeds that were attacked. GLMM analysis of the number of parasitized seeds in 2008 was not significant due to a convergence failure.

Dissection of 39 berries that had been exposed to attack by 35 female wasps in containers in the laboratory revealed wasp eggs in the fertilized seeds but neither eggs nor larvae in the unfertilized seeds. The proportion of fertilized seeds with wasp eggs was significantly greater than that of unfertilized seeds (Fisher's exact test, $\mathrm{P}<$ 0.001) (Table 3). After the end of the first flight there were no wasp eggs or larvae in the 96 fertilized and 22

TABLE 3. Oviposition response of Macrodasyceras hirsutum females to fertilized and unfertilized seeds of Ilex integra in the laboratory.

\begin{tabular}{|c|c|c|c|c|c|c|}
\hline \multirow{2}{*}{ Repetition } & \multirow{2}{*}{$\begin{array}{c}\text { No. of seeds } \\
\text { examined }\end{array}$} & \multicolumn{2}{|c|}{ No. of fertilized seeds } & \multicolumn{2}{|c|}{ No. of unfertilized seeds } & \multirow{2}{*}{$P$ value } \\
\hline & & With eggs & Without eggs & With eggs & Without eggs & \\
\hline 1 & 76 & 18 & 34 & 0 & 24 & $<0.001$ \\
\hline 2 & 78 & 12 & 56 & 0 & 10 & $>0.05$ \\
\hline Total & 154 & 30 & 90 & 0 & 34 & $<0.001$ \\
\hline
\end{tabular}


TABLE 4. Oviposition response of Macrodasyceras hirsutum females to unfertilized and fertilized seeds of Ilex integra in the field. The unfertilized seeds were produced in the field by flowers on branches enclosed in pollen exclusion bags and fertilized seeds by naturally fertilized flowers.

\begin{tabular}{|c|c|c|c|c|c|c|c|c|}
\hline \multirow{3}{*}{ Tree code } & \multicolumn{5}{|c|}{ No. of unfertilized seeds } & \multirow{2}{*}{\multicolumn{2}{|c|}{$\begin{array}{l}\text { No. of seeds in naturally } \\
\text { fertilized berries }\end{array}$}} & \multirow{3}{*}{$P$ value } \\
\hline & \multirow{2}{*}{$\begin{array}{c}\text { Total } \\
\text { examined }\end{array}$} & \multicolumn{2}{|c|}{ Exposed to wasps } & \multicolumn{2}{|c|}{ Isolated from wasps } & & & \\
\hline & & With eggs & Without eggs & With eggs & Without eggs & With eggs & Without eggs & \\
\hline F29 & 83 & 0 & 44 & 0 & 39 & 9 & 51 & $<0.01$ \\
\hline Kiwa & 380 & 0 & 140 & 0 & 240 & 0 & 60 & NA \\
\hline Tsu \#2 & 79 & 0 & 19 & 0 & 60 & 26 & 35 & $<0.001$ \\
\hline Total & 542 & 0 & 203 & 0 & 339 & 35 & 146 & $<0.001$ \\
\hline
\end{tabular}

${ }^{a}$ Naturally fertilized berries contained both fertilized and unfertilized seeds when exposed to wasps. See Table 2 for reference.

${ }^{\mathrm{b}}$ Difference in the proportion of unfertilized seeds with eggs after exposure to wasps and the proportion of the seeds in naturally fertilized berries was tested using Fisher's exact test. NA - not applicable.

unfertilized seeds in the 29 berries remaining in the bags on the two trees.

\section{Oviposition response of the wasps to unfertilized seeds in the field}

Dissection of 85 berries confined in bags for the 3.5 months when pollination occurred and the wasps were flying, revealed that all the seeds were $0.5-1.0 \mathrm{~mm}$ long and undeveloped, indicating that the bags successfully prevented pollination (Table 4). Dissection of the berries exposed to wasps in the field revealed neither eggs nor larvae in unfertilized seeds even one month after the wasp oviposited (Table 4). Fisher's exact test showed that the percentage parasitism of artificially unfertilized seeds by wasps was significantly lower than that of untreated seeds on each of two trees, F29 and Tsu\#2, although it was impossible to calculate the probability for another tree, Kiwa, as neither types of seed contained eggs or larvae (Table 4). These results indicate that wasps are reluctant to oviposit in unfertilized seeds.

\section{DISCUSSION}

The present study showed that Macrodasyceras hirsutum lays eggs in fertilized seeds but rarely in unfertilized seeds in the field, indicating selective oviposition. This was confirmed in the laboratory. Selection of oviposition sites by phytophagous insects is crucial for the fate of progeny, especially when immatures cannot move from one host to another (Desouhant, 1998; Stamps \& Linit, 2002). Macrodasyceras hirsutum larvae develop and pupate in the seed; therefore, it is suggested that the selection of nutritious seeds by female wasps may increase their fitness via the increased survival and reproduction ability of their progeny.

Few Macrodasyceras hirsutum eggs were recorded in unfertilized, small seeds in the field. Megastigmus spermotrophus, which oviposits before the seeds of its host are fertilized, can develop in unfertilized ovules (Rappaport et al., 1993; Rouault et al., 2004). The presence of Macrodasyceras hirsutum eggs in unfertilized seeds can be explained by either erroneous oviposition or the accumulation of storage material within unfertilized seeds that is induced by wasp oviposition and/or immature stages. Erroneous oviposition would indicate that wasps avoid ovipositing in unfertilized seeds whereas host manipula- tion by wasps indicates they oviposit in unfertilized seeds and that the unfertilized seed is induced to grow by the wasp. Wasps presented with unfertilized seeds were reluctant to oviposit, which indicates that wasps possibly oviposited in unfertilized seeds erroneously. The results presented indicate that Macrodasyceras hirsutum wasps selectively oviposit in fertilized seeds of Ilex integra, which supports Rouault et al. (2004) hypothesis.

A substantial proportion of Ilex integra berries did not contain fertilized seeds (Table 1). Although fertilized seeds were larger than unfertilized seeds, berry size did not depend on the number of fertilized seeds or endocarps they contained. Thus, Ilex integra uses energy and matter to produce berries even if they contain no fertilized seeds. Unfertilized seeds are nonviable and apparently unlikely to contribute to the fitness of a tree. Such seeds and seedless berries may, however, increase plant fitness by reducing the loss of viable seeds (Traveset, 1993). Ghazoul \& Satake (2009) suggest that selfed seeds are retained and develop during the period when predators are attacking the seeds in order to reduce loss of outcrossed seeds. Macrodasyceras hirsutum is the only species of wasp attacking the seed of Ilex integra and rarely oviposits in unfertilized seeds therefore in this case the unfertilized seeds do not act as a sink for this insect's eggs. There is two plausible reasons why Ilex integra trees retain seedless berries. One, it takes energy and time for wasps to insert their ovipositor through the flesh of a berry and the hard endocarp of a seed before it can determine whether it is fertilized or not. Berry size had no effect on the number of parasitized seeds, which may suggest that Macrodasyceras hirsutum is unable to determine the presence of fertilized seeds before inserting its ovipositor into the seeds. If the cost is large, the number of eggs deposited may be reduced. The other reason is the possible contribution of seedless berries to the dispersal of viable seeds by birds, because seedless berries develop normally and turn red in autumn (Takagi \& Togashi, unpubl.) and trees with abundance of red berries are more likely to attract more seed-dispersing birds than those with few red berries. Further studies on the ecological and evolutional roles of seedless berries are needed.

ACKNOWLEDGEMENTS. We are grateful to K. Kamijo for his identification of Macrodasyceras hirsutum. We are also 
grateful to $\mathrm{H}$. Ishibashi and S. Goto of the Laboratory of Forest Zoology, the University of Tokyo, for their assistance with making the bags used to prevent wasps ovipositing in berries.

\section{REFERENCES}

BoučEK Z. 1988: Australasian Chalcidoidea (Hymenoptera): A Biosystematic Revision of Genera of Fourteen Families, with a Reclassification of Species. CAB International, Wallingford, $832 \mathrm{pp}$.

Desouhant E. 1998: Selection of fruits for oviposition by the chestnut weevil, Curculio elephas. Entomol. Exp. Appl. 86: 71-78.

Esau K. 1977: Anatomy of Seed Plants. 2nd ed. John Wiley \& Sons, New York, 550 pp.

FUKUI A.W. 1995: The role of the brown-eared bulbul Hypsipetes amaurotis as a seed dispersal agent. Res. Popul. Ecol. 37: $211-218$.

Ghazoul J. \& Satake A. 2009: Nonviable seed set enhances plant fitness: the sacrificial sibling hypothesis. Ecology 90: 369-377.

Grissell E.E. \& DesJardins C.A. 2002: A revision of Bootania Dalla Torre and recognition of Macrodasyceras Kamijo (Hymenoptera: Torymidae). J. Hym. Res. 11: 279-311.

JANZEN D.H. 1970: Herbivores and number of tree species in tropical forests. Am. Nat. 104: 501-528.

Kamiso K. 1981: Description of the male and other notes on Macrodasyceras hirsutum (Hymenoptera: Torymidae). Akitu (N.S.) 38: 1-4.

Katsumata M., Mori T. \& Yokoyama T. 1998: Seeds of Woody Plants in Japan Angiospermae. Japan Forest Tree Breeding Association, Tokyo, 410 pp. [in Japanese].
Miyawaki A., Okuda S. \& MochizuKi R. 1983: Handbook of Japanese Vegetation. Rev. ed. Shibundo, Tokyo, 872 pp. [in Japanese].

Rappaport N., Mori S. \& Rogues A. 1993: Estimating effect of Megastigmus spermotrophus (Hymenoptera: Torymidae) on Douglas-fir seed production: the new paradigm. J. Econ. Entomol. 86: 845-849.

Rouault G., Turgeon J., Candau J.-N., Roques A. \& von ADERKAS P. 2004: Oviposition strategies of conifer seed chalcids in relation to host phenology. Naturwissenschaften 91 : 472-480.

Stamps W.T. \& Linit M.J. 2002: Oviposition choice by the black walnut curculio (Coleoptera: Curculionidae): A ten-year study. Environ. Entomol. 31: 281-284.

Traveset A. 1993: Deceptive fruits reduce seed predation by insects in Pistacia terebinthus L. (Anacardiaceae). Evol. Ecol. 7: $357-361$.

von Aderkas P., Rouault G., Wagner R., Chiwocha S. \& Roques A. 2005a: Multinucleate storage cells in Douglas-fir (Pseudotsuga menziesii (Mirbel) Franco) and the effect of seed parasitism by the chalcid Megastigmus spermotrophus Wachtl. Heredity 94: 616-622.

von Aderkas P., Rouault G., Wagner R., Rohr R. \& Roques A. 2005b: Seed parasitism redirects ovule development in Douglas fir. Proc. R. Soc. (B) 272: 2225-2235.

Zangerl A.R., Berenbaum M.R. \& Nitao J.K. 1991: Parthenocarpic fruits in wild parsnip: decoy defence against a specialist herbivore. Evol. Ecol. 5: 136-145.

Received October 26, 2009; revised and accepted December 30, 2009 